\title{
ACCESO LIBRE Y CONSERVACIÓN DE COSTAS EN EL DERECHO ROMANO. CONTROVERSIAS ACTUALES EN ARGENTINA
}

\author{
ABELENDA, Virginia ${ }^{1}$
}

SUMARIO: 1.- Ripae: res in publico usu iuris gentium. 2.- Carácter público del curso de agua y el aqua profluens como res commune omnium. 3.- Defensa del ambiente fluvial y ribereño: interdictos de fluminibus publicis y extensiones labeonianas. 3.1.- Operis novi nuntiatio. 3.2.- Cautio damni infecti. 4.- Referencias a interdictos sobre los lagos. 5.- Algunos casos actuales en Argentina y la reforma del Código Civil. 6.- Conclusiones.

\section{1.- Ripae: res in publico usu iuris gentium}

En el derecho romano, al ser considerados casi o todos los ríos y puertos públicos según respectivamente Marciano (jurista del período clásico tardío, s. III d.C.), y luego la drástica concepción justinianea (s. VI d.C.), era común a todos el derecho de pescar en ellos:

Marc., 3 inst., D.1.8.4.1

Sed flumina paene omnia et portus publica sunt. ${ }^{2}$

I.2.1.2. Flumina autem omnia et portus publica sunt: ideoque ius piscandi omnibus commune est in portubus fluminibusque. ${ }^{3}$

Es posible que Marciano se refiriera a flumina en sentido genérico, y el redactor de las Instituciones a los ríos en sentido técnico, en antítesis a los torrentes y arroyos, por lo que podría tratarse de una antinomia aparente y de una mera interpolación formal. La palabra flumen tiene un significado amplio y vulgar que comprende también a los torrentes, y uno más restringido, técnico, relativo solamente a los cursos de agua perennes. En el Digesto, por lo tanto, está insertada la limitación tal vez con el fin de reafirmar que los torrentes como tales no son públicos. En las Instituciones se señala como consecuencia de la publicidad de los ríos que todos pueden pescar en ellos, pero ha sido notado que bajo este aspecto, también se consideraría público el mar, que por el contrario es una res commune omnium. El paso del Digesto, por su parte, dice que casi todos los ríos son públicos, lo cual significa que había también ríos privados. ${ }^{4}$

\footnotetext{
${ }^{1}$ Doctora en Derecho por la Universidad de Roma II "Tor Bergata", Profesora de la Universidad de Buenos Aires y de la Escuela de Derecho de la Universidad Torcuato Di Tella.

${ }^{2}$ MARCIANO; Instituta, libro III. Pero casi todos los ríos y los puertos son públicos.

${ }^{3}$ Más todos los ríos y los puertos son públicos; y por tanto, es común a todos el derecho de pescar en el puerto y en los ríos.

${ }^{4}$ Cfr. J.M. ALBURQUERQUE, Interdictum ne quid in flumine publico repave eius fiat, quo peius navigetur (D. 43.12.1pr.) en SDHI 71 (2005), 201-202, v. así Sen. Nat. Quaest. 3.11.12; Fest. v. torrens (ed Lipsay 483-484); Paul. 49 ad ed., D. 39.3.2.9; Ulp. 68 ad ed., D. 43.12.1.2. Asimismo, D. 43.12.1. Existen supuestos para el A., en los que basándose en la utilidad pública se pueda extraer un beneficio para la colectividad. Podría darse la posibilidad de que un río privado parezca público debido a la circunstancia de uso público en la praxis; si bien no parece acertado extraer de esas motivaciones consecuencias que puedan amparar
} 
Ulpiano, 57 ad ed., D.47.10.13.7, haciendo referencia a la procedencia de la acción de injurias, sostiene que al ser ciertamente el mar común de todos, y también sus orillas, como el aire, muchísimas veces se resolvió por rescripto, que no se le podía prohibir a uno que pesque en él, opinión que comparten Pomponio y la mayoría; sin embargo, en caso de impedimento de pesca por parte del dueño de un lago privado el ejercicio de esta acción queda excluida:

Si quis me prohibeat in mari piscari vel everriculum (quod Graece ....... dicitur) ducere, an iniuriarum iudicio possim eum convenire? sunt qui putent iniuriarum me posse agere: et ita Pomponius et plerique esse huic similem eum, qui in publicum lavare vel in cavea publica sedere vel in quo alio loco agere sedere conversari non patiatur, aut si quis re mea uti me non permittat: nam et hic iniuriarum conveniri potest. Conductori autem veteres interdictum dederunt, si forte publice hoc conduxit: nam vis ei prohibenda est, quo minus conductione sua fruatur. Si quem tamen ante aedes meas vel ante praetorium meum piscari prohibeam, quid dicendum est? me iniuriarum iudicio teneri an non? et quidem mare commune omnium est et litora, sicuti aer, et est saepissime rescriptum non posse quem piscari prohiberi: sed nec aucupari, nisi quod ingredi quis agrum alienum prohiberi potest. Usurpatum tamen et hoc est, tametsi nullo iure, ut quis prohiberi possit ante aedes meas vel praetorium meum piscari: quare si quis prohibeatur, adhuc iniuriarum agi potest. In lacu tamen, qui mei dominii est, utique piscari aliquem prohibere possum. ${ }^{5}$

Y cfr. Javoleno, 11 ex Cassio, D.50.16.112, el litoral es público hasta donde llegan las olas máximas, a no ser que los lagos fueran en su totalidad de propiedad privada:

la idea de negar la sustancial diferencia entre río privado y río público formulada por Ulpiano, que responden al significado más auténtico de las expresiones que él mismo utiliza de forma tajante y que no ofrecen lugar a dudas.

${ }^{5}$ ULPIANO; Comentarios al Edicto, libro LVII. 7.-Si alguno me prohibiera pescar en el mar, o llevar la red que en griego se llama buitron, ¿podré acaso demandarlo con la acción de injurias? Hay quienes opinan que puedo ejercitar la acción de injurias; y así opina Pomponio; y los más, que a este es semejante el que no consintiera que uno lave en lugar público, o que se siente en las gradas del anfiteatro, o que en algún otro lugar conduzca carro, se siente, o converse, o si alguien no permitiera que yo use de una cosa mía; porque también este puede ser demandado con la acción de injurias. Mas al arrendatario le dieron los antiguos interdicto, si acaso tomó públicamente el arrendamiento, porque se debe prohibir que se le haga violencia para que no disfrute de su arrendamiento. Pero si yo le prohibiera a alguno que pesque delante de mi casa, o delante de mi palacio de campo, ¿que se hade decir, que estoy, o no, sujeto a la acción de injurias? Y ciertamente que el mar es común de todos, y también sus orillas, como el aire, y muchísimas veces se resolvió por rescripto, que no se le podía prohibir a uno que pesque; pero tampoco se le puede prohibir que caze, sino que entre en fundo ajeno. Fue, sin embargo, también de uso, aunque no fundado en ningún derecho, que a cualquiera se le pudiera prohibir que pescara delante de mi casa, o de mi palacio de campo; por lo que si a alguno se le prohibiera, aun se puede ejercitar la acción de injuria. Pero a la verdad, en lago, que es de mi dominio, puedo prohibirle a alguien que pesque. Cfr. S. CASTÁN PÉREZ GÓMEZ, Régimen jurídico de las concesiones administrativas en el derecho romano, Madrid 1996, 219 y nt. (51), más adelante, esta costumbre se volvió legal, pues el emperador León VI apelado el Filósofo-, rompió con la tradición anterior y reconoció un dominio privado sobre el espacio de mar y sobre la pesca que se encontrase enfrente de las casas ribereñas (Coll. II, Nov. 56). Según G. PURPURA, "Liberum mare", acque territoriali e riserve di pesca nel mondo antico, en Annali del Seminario Giuridico dell'Università di Palermo XLIX (2004), 172, ello se deberá a una nueva tecnología de pesca de gran relevancia económica, la trampa con la cámara de la muerte instalada en mar abierto, que favorecerá la decadencia de la antigua concepción del mar como cosa común, concurriendo así a avalar las pretensiones de particulares y estados territoriales sobre aguas, ahora reivindicadas como nostrae, volviendo teóricamente posible un aprovechamiento público en sentido patrimonial del ambiente marino, antes considerado un verdadero y propio abuso. 
Litus publicum est eatenus, qua maxime fluctus exaestuat. Idemque iuris est in lacu, nisi is totus privatus est. ${ }^{6}$

No obstante, según Paulo, el jurista augusteo Labeón , 6 pith. a Paul. epitom., D.41.1.65.1, a inicios del Principado, afirmaba que las riberas (ripae) próximas a los ríos y las costas próximas al mar también son públicas, aunque en ellas haya islas cuya propiedad pertenece a alguien, y se tiene el mismo derecho respecto a un campo contiguo:

Si qua insula in flumine propria tua est, nihil in ea publici est. PAULUS: immo in eo genere insularum ripae flumini et litora mari proxima publica sunt, non secus atque in continenti agro idem iuris est. ${ }^{7}$

Luego de ello, en las fuentes romanas se encuentra una categoría más amplia que la de cosas públicas como es la de res in usu publico iuris gentium, así lo demuestran varios testimonios presentes en ellas, como aquel de Gayo en el Digesto, quien sostiene que es público por derecho de gentes el uso de las riberas, así como el del mismo río, cfr. Gai., 2 rer. cott. sive aur., D.1.8.5pr.:

Riparum usus publicus est iure gentium sicut ipsius fluminis. Itaque navem ad eas appellere, funes ex arboribus ibi natis religare, retia siccare et ex mare reducere, onus aliquid in his reponere cuilibet liberum est, sicuti per ipsum flumen navigare. Sed proprietas illorum est, quorum praediis haerent: qua de causa arbores quoque in his natae eorundem sunt..$^{8}$

En igual sentido, se pronuncia Paulo, pero va más allá, al afirmar que las riberas que están junto al fundo vendido no son de nadie, y están para el uso de todos por derecho de gentes, así como las vías públicas, cfr. Paul., 21 ad ed., D.18.1.51:

Litora, quae fundo vendito coniuncta sunt, in modum non computantur, quia nullius sunt, sed iure gentium omnibus vacant: nec viae publicae aut loca religiosa vel sacra. Itaque ut proficiant venditori, caveri solet, ut viae, item litora et loca publica in modum cedant. ${ }^{9}$

Los litora que son adyacentes a los fundos de tierra vendidos no caen bajo el modus de la actio de modo agri porque son nullius. Pero además, pueden, en base a este fragmento, señalarse dos elementos del significado de ius gentium: las normas concernientes a las riberas son aplicables a los Romanos y a los peregrinos, y ellas son comunes al derecho romano y a

${ }^{6}$ JAVOLENO; Doctrina de Casio, libro XI. El «litoral» es público hasta donde llegan las olas máximas; y el mismo derecho hay respecto a los lagos, a no ser que todo él fuera privado.

${ }^{7}$ LABEON; Dichos recopilados por Paulo, libro VI. - Si en un río hay una isla propia tuya, nada de ella es del público. Y dice Paulo: aun en esta clase de islas, las riberas próximas al río, y las costas próximas al mar son públicas, no de otra suerte que hay este mismo derecho en cuanto al campo contiguo.

${ }^{8}$ GAYO; Diario, libro II.- Es público por el derecho de gentes el uso de las riberas, así como el del mismo río. Y así, cualquiera tiene libertad para acercar a ellas su nave, atar cuerdas de los arboles allí nacidos, tender a secar y sacar del mar las redes, y acomodar en ellas alguna carga, así como navegar por el mismo río. Pero la propiedad es de aquellos con cuyos predios colindan; por cuya causa son también de los mismos los árboles en ellas nacidos.

${ }^{9}$ PAULO; Comentarios al Edicto, libro XXI.- Las riberas que están junto al fundo vendido no se computan para la cabida, porque no son de nadie, sino que por derecho de gentes están para el uso de todos; y tampoco las vías públicas, o los lugares religiosos, o sagrados; y así, para que le aprovechen al vendedor, suele darse caución de que los caminos, así como las riberas y los lugares públicos se comprenden en la cabida. 
todos los sistemas jurídicos conocidos por los Romanos. ${ }^{10}$

Asimismo, nuevamente Gayo, sostiene que el nuevo cauce natural de un río, que comenzó a correr por otra parte, comienza también a ser de aquel derecho de quien es también el mismo río, ello es, público por derecho de gentes, cfr. Gai., 2 rer. cott. sive aur., D. 41.1.7.5, en el título referido a la adquisición del dominio de las cosas:

Quod si toto naturali alveo relicto flumen alias fluere coeperit, prior quidem alveus eorum est, qui prope ripam praedia possident, pro modo scilicet latitudinis cuiusque praedii, quae latitudo prope ripam sit: novus autem alveus eius iuris esse incipit, cuius et ipsum flumen, id est publicus iuris gentium. Quod si post aliquod temporis ad priorem alveum reversum fuerit flumen, rursus novus alveus eorum esse incipit, qui prope ripam eius praedia possident. Cuius tamen totum agrum novus alveus occupaverit, licet ad priorem alveum reversum fuerit flumen, non tamen is, cuius is ager fuerat, stricta ratione quicquam in eo alveo habere potest, quia et ille ager qui fuerat desiit esse amissa propria forma et, quia vicinum praedium nullum habet, non potest ratione vicinitatis ullam partem in eo alveo habere: sed vix est, ut id optineat. ${ }^{11}$

\section{2.- Carácter público del curso de agua y el aqua profluens como res commune omnium}

El carácter público de las aguas, sea las provenientes de los ríos como de los acueductos etc., estaba dado por su ubicación en tierra pública y por su perennidad ${ }^{12}$, entre ellas, los cursos de agua comprendidos en el ager publicus -también en los municipios y colonias-, como los ríos, acueductos, estanques, torrentes, lagos, arroyos, las fuentes que

${ }^{10}$ H. ANKUM, «Litora maris» et «longi temporis praescriptio» en INDEX 26 (1998), 363, 369. V. O. LENEL, Essai de reconstitution de l'édit perpétuel / ouvrage traduit en français par Fréderic Peltier, Paris 1901: [De modo agri (E.74)].

${ }^{11}$ GAYO; Diario, libro II. Pero si habiendo dejado todo su cauce natural el río hubiere comenzado a correr por otra parte, el anterior cauce es ciertamente de los que poseen predios junto a la orilla; por supuesto, con arreglo a la latitud que cada predio tenga junto a la orilla; mas el nuevo cauce comienza a ser de aquel derecho de quien es también el mismo río, esto es, público por derecho de gentes. Mas si después de algún tiempo el río hubiere vuelto a su cauce anterior, el nuevo cauce comienza a ser otra vez de los que poseen predios junto a su orilla. Pero si el nuevo cauce hubiere ocupado todo el campo de alguno, aunque el río hubiere vuelto a su cauce anterior, sin embargo, aquel de quien había sido este campo no puede tener parte alguna en este cauce, porque también dejo de existir el campo que había habido, por haber perdido su propia forma; y como no tiene ningún predio vecino, no puede tener por razón de vecindad parte alguna en este cauce; pero es muy difícil que este prevalezca. G. LOMBARDI, Ricerche in tema di «ius gentium», Milano 1946, 51, 54-55, 142, nota como un fuerte indicio de alteración de los compiladores, la divergencia sustancial entre Instituciones de Gayo y Res cottidianae -de las cuales se niega verosímilmente (según el A.) pertenezcan a Gayo- en materia de clasificación de las res, en donde aparece precisamente, frente a la esquemática simpleza de la clasificación gayana de las Instituciones en res humani iuris: ... aut publicae sunt aut privatae, el concepto de res publicae iuris gentium. Por otra parte, el A. no concuerda con la opinión de BRANCA, para quien ya en el transcurso del II s. d.C. se habría vislumbrado una distinción en el ámbito de las res publicae: la observación de los principios operativos en el seno de otros pueblos demostraba que los ríos a la par de las costas y del mar no sólo eran en todos lados de uso común, sino que lo eran independientemente de la voluntad y de la intervención del pueblo mismo. En tal modo, no sólo eran aislados de los teatros, de los foros, de las calles, etc., que el Estado mismo hacía construir y destinaba al uso de todos, sino que en un cierto sentido eran considerados, aún siendo del populus Romanus, como pertenecientes a la comunidad internacional: en efecto, el ius gentium es invocado, por Gayo (D. 41.1.7.5) y por Papiniano (D. 41.3.45) que lo sigue, no como fuente de la norma de la cual deriva la publicidad de la res, sino casi como un organismo al cual pertenece la cosa: los dos juristas afirman no sólo que los ríos y las costas (por ende, también el mar) son públicos iure gentium, sino además que son públicos iuris gentium.

${ }^{12}$ V. J. PLESCIA, The Roman Law on Waters, en INDEX 21 (1993), 440. 
alimentan los acueductos públicos, y en general, las aguas de montaña. ${ }^{13}$ Así lo afirma Casio, cfr. Ulp., 68 ad ed., D.43.12.1.3, opinión seguida por Celso así como por el mismo Ulpiano, al considerar ríos públicos aquellos que eran perennes:

Fluminum quaedam publica sunt, quaedam non. Publicum flumen esse Cassius definit, quod perenne sit: haec sententia Cassii, quam et Celsus probat, videtur esse probabilis. $^{14}$

Es decir, Casio Longino, maestro de la escuela sabiniana, y que vivió en el I s. d.C., comparte la misma opinión en este punto con Celso, que, unas décadas después, será la cabeza de la opuesta corriente de los proculeyanos. Ello significa una unanimidad de opiniones de la cual desciende su incontrovertible aceptación por los juristas contemporáneos y posteriores; y Ulpiano, en efecto, la expone sin someterla a discusión; sin embargo, la frase final videtur esse probabilis nos da la idea que ella no era unánimemente aceptada por la totalidad de los juristas, o sea, no es declarada vera. Ello así, porque según el sistema tradicional, si un curso de agua hubiese atravesado un fundo público habría sido público, mientras también un río perenne habría podido ser privado allí cuando hubiese atravesado un fundo en dominium de un privado. La regla de Casio rompe este automatismo, reconociendo el atributo público a un carácter natural del río, como es la perennidad de la corriente. Resulta evidente que la publicidad fundada sobre esta cualidad intrínseca del río, respondiese mejor a la generalidad de los usos a los cuales una corriente perenne podía servir, si se piensa en los intereses ligados a la navegación fluvial, a los de la agricultura ribereña, que se servían de ella para la irrigación de sus fundos, o a los de las ciudades que la usaban para el suministro hídrico. El elemento que distingue los ríos públicos de los privados está constituido por la perennidad o menos del curso de agua, aquel que discurre todo el año con corriente más o menos constante es público, mientras aquel dotado de un régimen hídrico variable, en función sobre todo de las precipitaciones, es privado. Es por este motivo que Ulpiano, para ejemplificar en qué consiste un torrente, se sirve de la palabra griega que identifica un río que discurre prevalentemente en invierno, cuando las lluvias son abundantes. ${ }^{15}$ Los ríos públicos están sujetos a una serie de cautelas dirigidas a garantizar la regularidad del aporte hídrico para los usos públicos, desde el suministro necesario para la irrigación agrícola y para los usos potables, hasta llegar al otro fundamental constituido por la navegación fluvial; y desde el momento que la navegación es una de las más importantes funciones colectivas de un río, el río navegable es siempre público, aunque no todos los ríos públicos son navegables. En conclusión, después del acogimiento de la sententia de Casio, el requisito mínimo para reconocer la publicidad de un río está constituido no por la navegabilidad sino por la perennidad de la corriente. Un río es de todos modos público si, aun no poseyendo la aptitud necesaria para la navegación, tiene una suficiente para asegurar las otras utilidades colectivas. ${ }^{16}$

${ }^{13}$ CASTÁN PÉREZ GÓMEZ, Régimen jurídico de las concesiones administrativas en el derecho romano cit., 226.

${ }^{14}$ ULPIANO; Comentarios al Edicto, libro LXVIII.- Algunos ríos son públicos, y otros no; Casio define que es río público el que sea perenne; esta opinión de Cassio, que también aprueba Celso, parece que es admisible. Cfr. ALBURQUERQUE, Interdictum ne quid in flumine publico repave eius fiat, quo peius navigetur (D. 43.12.1pr.) cit., 212, Casio Longino era un jurista versadísimo en tema de aguas, por lo tanto, no resulta ilógico que contribuyera a fijar un criterio general para establecer la publicidad de los ríos.

${ }^{15}$ V. Ulp., 68 ad ed., D.43.12.1.2, quien afirma que unos ríos son perennes, y otros torrenciales; es perenne el que siempre corre, torrente el que corre en invierno. Pero si en algún estío se secara el que en otras estaciones corría perenne, no por eso es menos perenne o deja de serlo.

${ }^{16}$ Cfr. M. FIORENTINI, Struttura ed esercizio della servitù d'acqua, en AA. VV., Contributi romanistici, (Quaderno n. 8 del Dipartimento di Scienze Giuridiche, Università degli Studi di Trieste), Trieste 
Sin perjuicio de ello, algunos autores observan que ningún texto de la jurisprudencia, ni disposición normativa alguna permite separar netamente las aguas privadas de las públicas; si bien, dentro de la gama de las aguas superficiales, se destaca la disciplina jurídica que afecta especialmente a los ríos públicos. En principio, todas las aguas que manaban o discurrían por los terrenos que formaban parte del ager publicus, que todavía no habían sido divididos o asignados a particulares, ciudadanos o latinos, conservaban la naturaleza y condición pública. Es decir, como para todas las cosas públicas, la publicidad dependía del título, o bien se atendía a la vetustas. Luego, cuando progresivamente va cediendo el ager publicus de frente al ager privatus, y prevalecen los agri arcifinii de frente a los agri limitati, la jurisprudencia clásica intenta establecer la condición pública o privada de las aguas de forma autónoma, según criterios generales deducidos de la importancia o condición natural y la destinación económico-social, sin embargo, la distinción aparece elaborada únicamente en relación con los cursos de agua, o por la importancia de los mayores entre ellos, los ríos, o por la necesidad de limitar rigurosamente el ámbito de aplicación de los interdictos de fluminibus. Con ello, la jurisprudencia habría querido determinar criterios más seguros para la publicidad de los ríos, que respondieran mejor a las nuevas condiciones sociales, reconociendo el uso público de los cursos de agua más grandes, y, a su vez, analizando una serie de medidas administrativas que permitieran todas las posibles formas de uso de los ríos que necesitaran los ciudadanos (navegación, uso de las orillas, derivaciones de agua, etc.), con valoraciones críticas que impiden el uso excesivo y el abuso incontrolado de los cursos de agua; por tanto, es de los criterios generales que se desprenden de la condición natural y de la valoración económico-social que se fija la publicidad o el carácter privado de ellos, el que aparece controlado también por los interdictos, de donde se puede comprobar la destacada relevancia que se otorga al sistema de uso colectivo sobre estas aguas públicas, con características coincidentes en el derecho clásico, postclásico y justinianeo. ${ }^{17}$

Sin embargo, llama la atención que en esta avanzada época ulpianea, con los grandes logros de la administración pública, el jurista no aludiera ni de forma soslayada a una posible

2003, 57-60, el comportamiento de los usuarios privados que pudiesen empeorar el estado de los ríos era sancionado con los procedimientos de urgencia vistos, los interdicta, elaborados por el pretor en su edicto para singulares hipótesis de turbaciones, con los cuales el magistrado prohibía la construcción de obras en el lecho de los ríos o sobre las riberas que pudiesen perjudicar la navegación sobre un río público navegable (D. 43.12); impedía las manipulaciones de los cursos de agua realizados por ejemplo con apertura de incilia, o sea cortes en los bancos para instalar una derivación de agua, que se resolviesen en una modificación de las usuales modalidades de desplazamiento del río (D. 43.13); sancionaba los actos de violento impedimento dirigidos a obstaculizar a alguien en su facultad de navegar (D. 43.14); inhibía los comportamientos violentos dirigidos a impedir a alguien levantar diques antes inexistentes, o restaurar diques ya existentes, que sirviesen para tener bajo control el régimen de los ríos públicos (D. 43.15). Para algunas de estas hipótesis dañosas el pretor previó también otros interdictos con los cuales fuese posible remover las obras perjudiciales, si la activación de parte hubiese sido sucesiva a su edificación.

${ }^{17}$ ALBURQUERQUE, Interdictum ne quid in flumine publico repave eius fiat, quo peius navigetur $(D$. 43.12.1pr.) cit., 197-200, cfr. Front. de contr. Agr. 20.10. En general podrían considerarse en un principio públicas las fuentes de las montañas y las partes superiores de muchos cursos de agua, incluso los cursos de agua menores y no perennes, que nacían y fluían en las regiones montañosas, que pertenecían antiguamente al Estado romano, y que nunca fueron objeto de adsignatio durante la etapa republicana. Sólo más tarde fueron atribuidas a las civitates, y por lo tanto al fiscus, y fueron también objeto de algunas concesiones a possessores de grandes latifundios. Según P. MADDALENA, I beni comuni nel diritto romano: qualche valida idea per gli studiosi odierni (Lezione tenuta presso l'Istituto di diritto romano, della Facoltà di giurisprudenza dell’Università "La Sapienza" di Roma, il 06 giugno 2012-06-05), 34, pertenecen al populus todos los ríos que, aunque no navegables, tengan una cierta consistencia de agua, útil, por ejemplo, para las derivaciones, el riego y otros importantes usos. Por otra parte, de la pertenencia pública, según el A., es testimonio también el simple adjetivo "publicum", porque las res publicae, como la etimología enseña, no significa sino res populi (publicae/poplicae), ello es, del pueblo romano. 
determinación por elenco, o introduciendo como criterio complementario a la perennidad, la estimación, no ya específicamente sólo de los habitantes del entorno en general, sino la de las autoridades o magistrados competentes. Quizás el planteo de Ulpiano, siguiendo un criterio excesivamente clásico como era la perennidad, quería mantener una idea simplificadora de la publicidad fluvial, que no se apartara en exceso de las afirmaciones jurisprudenciales que encuadraban a los ríos dentro de los bienes de uso público, como las vías públicas, lo que le impedía conformar un criterio más pormenorizado que pudiera contribuir a cercenar de alguna forma el libre uso y aprovechamiento de los mismos. ${ }^{18}$

Por otro lado, también con Marciano, 3 inst., D.1.8.2pr., título dedicado en el Digesto a la división y cualidad de las cosas, se llega a la categoría más amplia de cosas comunes a todos por derecho natural:

Quaedam naturali iure communia sunt omnium, quaedam universitatis, quaedam nullius, pleraque singulorum, quae variis ex causis cuique adquiruntur. ${ }^{19}$

Y según el mismo Marc., 3 Inst., D. 1.8.2.1, son comunes a todos por derecho natural el aire, el agua corriente, el mar y sus costas:

Et quidem naturali iure omnium communia sunt illa: aer, aqua profluens, et mare, et per hoc litora maris. ${ }^{20}$

El fundamento y la especificidad de esta calificación se deben encontrar en los modos de uso, además, ella está dada en negativo, ello es, el no poder impedir a nadie el uso de tales cosas. $^{21}$

En cuanto al aqua profluens, se cree que su inclusión por Marciano en el elenco de las res communes omnium deba tratarse de una influencia extrajurídica, puesto que ella en realidad, no estaría sujeta a un régimen particular distinto del régimen del curso de agua al cual pertenece. ${ }^{22}$ El mar y sus costas, parecerían acercarse a las cosas públicas destinadas al uso público, ambas están abiertas por regla general al uso de todos. Pero, si el mar y el lido, en su régimen jurídico, presentan particularidades que los individualizan como res communes

${ }^{18}$ ALBURQUERQUE, Interdictum ne quid in flumine publico repave eius fiat, quo peius navigetur (D. 43.12.1pr.) cit., 215-216; cfr. A. AGUDO RUIZ, Rec. a Juan Miguel Alburquerque, La protección o defensa del uso colectivo de las cosas de dominio público: Especial referencia a los interdictos de publicis locis (loca, itinere, viae, flumina, ripae), en SDHI 71 (2005), 645, de nuevo Ulpiano, gran aportador al derecho público y administrativo, acude al sistema de citas para determinar la diferencia entre río público y privado: la perennidad, la navegabilidad, la magnitud o las circunstancias geográficas y la estimación social, cfr. D.43.12.1.1, 2 y 3. De estos criterios, elásticos y oscilantes, es el de la perennidad el esencial a la hora de considerar la publicidad fluvial.

${ }^{19}$ MARCIANO; Instituta, libro III. Algunas cosas son comunes a todos por derecho natural, otras son de la comunidad, otras no son de nadie, y la mayor parte son de particulares, las cuales se adquieren para cada cual por varias causas.

${ }^{20}$ MARCIANO; Instituta, libro III.- 1.- Y ciertamente son comunes a todos por derecho natural estas cosas: el aire, el agua corriente, y el mar, y consiguientemente las costas del mar.

${ }^{21}$ M. FIORENTINI, L'acqua da bene economico a res communis omnium a bene collettivo, en Quaderni del Dipartimento di Scienze Giuridiche 8. Contributi Romanistici Università degli Studi di Trieste (2003), 3 .

${ }^{22}$ L. CAPOGROSSI COLOGNESI, Ricerche sulla struttura delle servitù d'acqua in diritto romano, Milano 1966, 55 ss. 
omnium, encuentra entonces una razón de ser -aunque se la critique- la inclusión del aire y del aqua profluens. ${ }^{23}$

Antecedentes de este concepto de res communes omnium, se encuentran, por lo demás, ya en Cic., de off., 1.16.51: tam commune quam spiritus vivis [aer], mare fluctuantibus, litus eiectis; 52: "ex quo sunt communia: non prohibere aqua profluente, pati ab igne ignem capere", no obstante lo ilimitado del recurso agua según el mismo Cicerón; Plaut., Rud., 4.3.35: "Mare quidem commune certost omnibus". 38. "in mari inventast communi". 42: "dicant in mari communi captos"; Ovid., Met., VI.350: "quid prohibetis aquis? Usus communis aquarum est"; y Sen., de benef., V.28: "commune bonum era patere commercium maris et regnum humani generi relaxari". ${ }^{24}$ Está presente en estas locuciones no sólo una anticipación del concepto de 'bien común', sino además una primera señal del moderno 'derecho de acceso al agua', aunque las ideas de Cicerón se ubicarían sobre el plano moral o al máximo de iure condendo, y no serían indicativas de reglas jurídicas vigentes en los años en que él escribía. ${ }^{25}$

Finalmente, Justiniano, recogiendo la elaboración jurisprudencial precedente, también en la parte referente a la división de las cosas, dice respecto a ellas, que son por derecho natural comunes a todos: el aire, el agua corriente, el mar y las costas del mar, cfr. I.2.1.1:

\section{Et quidem naturali iure communia sunt omnium haec: aer et aqua profluens et mare et per hoc litora maris. ${ }^{26}$}

Marciano probablemente refleje la opinión de la mayoría en el período clásico tardío, ello es, de época severiana, caracterizada por una visión socialista y ecuménica estoica del Imperio, y, por ello, por una política de unificación cultural de éste, opinión que es seguida y reforzada por Justiniano, quien, en general, sigue a la jurisprudencia de este período ${ }^{27}$, no obstante la existencia de ciertas ambigüedades en las Institutas respecto a la calificación jurídica del mar y sus costas por un lado, o la no explicación de la calificación de comunes

${ }^{23}$ G. GROSSO, Rec. a A.G. Scherillo, Lezioni di diritto romano, Le cose I: Concetto di cosa. Cose extra patrimonium, en Scritti storico giuridici IV. Recensioni e Ricordi, Torino 2000, 212; V. V. ARANGIO RUIZ, Instituciones de derecho romano, Napoli 1973, 190-191; A. BURDESE, Manuale di diritto privato romano, Torino 1985, 173; para ALBURQUERQUE, Interdictum ne quid in flumine publico repave eius fiat, quo peius navigetur (D. 43.12.1pr.) cit., 205-206, no obstante, el uso común del agua corriente no parece que haya sido desatendido en el mundo romano, como podría desprenderse de las imprecisiones conceptuales que aporta la doctrina sobre el aqua profluens, basándose en los confusos textos que no aclaran suficientemente la definición en cuanto a su régimen jurídico. Si bien, parece claro que en la mayoría de los supuestos se reflejan ciertas asimilaciones que destacan el aspecto comunal (de uso común) y, con matices que engloban al lugar por donde discurren, público.

${ }^{24}$ Según PURPURA, “Liberum mare”, acque territoriali e riserve di pesca nel mondo antico cit., 191, la novedad, entonces, introducida en el III sig. d.C. por Marciano en D. 1.8.2.1 de la clasificación de las costas y del mar en la nueva categoría de las res communes omnium, preanunciada a través del reconocimiento de un uso común de algunas res en Ulpiano D. 39.2.24pr., según el cual el mare commune omnium est et litora, sicut aer (D. 47.10.13.7) debe ser notablemente redimensionada.

${ }^{25}$ L. SOLIDORO MARUOTTI, Il «civis» e le acque, en INDEX 39 (2011), 246; R. PERRUSO, The development of the doctrine of res communes in medieval and early modern Europe, en TIJD 1-2 (2002), 69, 93, 72 y nt. (19), 73-74; MADDALENA, I beni comuni nel diritto romano: qualche valida idea per gli studiosi odierni cit., 7-9.

${ }^{26}$ Y por derecho natural son en verdad comunes á todos estas cosas: el aire, el agua corriente y el mar, y por lo mismo las costas del mar.

27 PLESCIA, The Roman Law on Waters cit., 436, 438-439, 447; FIORENTINI, L'acqua da bene economico a res communis omnium a bene collettivo cit., 45. 
para el aire, mar, costas y agua corriente, y de públicas para los ríos, que pueden deberse, sin embargo, a la dificultad de integrar las varias opiniones de los juristas en un texto único. ${ }^{28}$

Para algunos autores, no resulta en algún modo comprobado que los juristas clásicos hayan considerado res communis omnium el aqua profluens de las aguas que discurrían por las fuentes a través del curso de los torrentes y de los ríos sobre los cuales existían servidumbres de acueducto. Por ello, se cree que la referencia de Marciano tenía que ver exclusivamente con la categoría de los ríos públicos. El texto de este jurista y el de las Instituciones justinianeas, que de aquel deriva, no habrían introducido un principio destinado a regular la condición de todas las aguas fluentes, principio que nunca los juristas romanos clásicos habrían conocido, sino que haría más bien referencia a la posibilidad de parte de cualquier particular de utilizar las aguas de los cursos públicos. La concepción del aqua profluens como res communis omnium, distinta de la condición jurídica del curso de agua al cual pertenece, se encontraría en contraste con el hecho que mientras para extraer agua de una fuente privada es necesario constituir la servidumbre de aquae haustus, para utilizar el agua de un río público es suficiente la constitución de una servidumbre de pasaje. Además, el término profluens es traducido por Teófilo (Paraphr. 2.1.1) y Stefano (Bas. 46.3.2 sc. 1) con un término que significa perennis y que por lo tanto, si es usado a propósito de cursos de agua, servía para distinguir los públicos de los privados. En fin, las Instituciones Justinianeas, después de haber hecho el elenco de las res communes omnium, pasan, en los párrafos sucesivos, a examinarlas más en particular, y, en relación al aqua profluens mencionan exclusivamente la categoría de los ríos públicos. ${ }^{29}$

\section{3.- Defensa del ambiente fluvial y ribereño: interdictos de fluminibus publicis y extensiones labeonianas}

Ulpiano, 68 ad ed., D.43.12.1.12, afirma que el Pretor no prohíbe todo lo que se hace en un río público u orilla, sino cuando se hiciera algo que haga peor la estancia en él y la navegación, es decir, en los ríos navegables. Pero asimismo, refiere la opinión de Labeón, quien consideraba que no era injusto que también si en un río no navegable, se hiciera algo de modo que se seque, o se impida la corriente del agua, competa el interdicto útil, con el fin de evitar que se haga violencia para quitar, demoler, limpiar o restablecer a su primer estado

${ }^{28}$ PERRUSO, The development of the doctrine of res communes in medieval and early modern Europe cit., 75; Según ANKUM, «Litora maris» et «longi temporis praescriptio» cit., 370, aparentemente se quiso evitar el término res. Los litora maris tienen características comunes con las res publicae, las res nullius y las communia omnium; para P. MADDALENA, Danno pubblico ambientale, Rimini 1990, 74-78, 142-146, de todos modos, la indicación querría hacernos entender que es necesario distinguir entre curso de agua y agua corriente. Es res commune omniun el agua que discurre por el río, no el río en sí, el cual como sabemos de otras fuentes es, en cambio, una res publica, es decir, un bien perteneciente al populus. Sin embargo, el A. no advierte que las fuentes hacen alusión a los ríos también como res publicae iuris gentium. El A. mismo resalta, por otra parte, que se habla además de res communes omnium, refiriéndose no sólo a los homines, sino también a los animales, cosas que por naturaleza no podían ser sustraídas a ninguno. La categoría, correctamente entendida, es decir, referida al ius gentium o al ius naturale, demuestra claramente que los Romanos tuvieron una concepción no sólo nacional, sino también universal del derecho, junto al derecho de la civitas (ius civile), estaba también el derecho de todos los hombres (ius gentium) y de todos los seres vivos (ius naturale). El principio informador era ubi societas, ibi ius, siendo la comunidad la fuente del derecho.

${ }^{29}$ CAPOGROSSI COLOGNESI, Ricerche sulla struttura delle servitù d'acqua in diritto romano cit., 55-57, 68, para el A., dada la creciente importancia que el molino de agua estaba destinado a asumir en los últimos siglos del Imperio, no se comprende tampoco el desinterés testimoniado por la categoría del aqua profluens como res communis omnium por los juristas y la cancillería imperial. Sobre el agua como res commune omnium v. también V. ABELENDA, El agua como res commune omnium. Interdictos y acciones procesales romanas en defensa de su acceso y conservación (Buenos Aires, en prensa). 
(según arbitrio de hombre bueno) la obra que se haya hecho en el cauce del río o en la orilla por la cual se hizo peor el paso o su corriente:

Non autem omne, quod in flumine publico ripave fit, coercet praetor, sed si quid fiat, quo deterior statio et navigatio fiat. Ergo hoc interdictum ad ea tantum flumina publica pertinet, quae sunt navigabilia, ad cetera non pertinet. Sed Labeo scribit non esse iniquum etiam si quid in eo flumine, quod navigabile non sit, fiat, ut exarescat vel aquae cursus impediatur, utile interdictum competere 'ne vis ei fiat, quo minus id opus, quod in alveo fluminis ripave ita factum sit, ut iter cursus fluminis deterior sit fiat, tollere demoliri purgare restituere viri boni arbitratu possit', ${ }^{30}$

Por ello, para algunos autores ${ }^{31}$, de este fragmento resultaría también que Labeón consideraba extendible en vía útil tal interdicto a cualquier río, aún no público y no navegable, contra una vastísima gama de actividades que deterioraran el curso de agua, la recomposición del cual en sede de relativo interdicto restitutorio se indica con las expresiones tollere demoliri purgare restituere, entre las que en particular el purgare se referiría a la limpieza de las aguas fluviales como tutela de su salubritas en el interés de todos. Al contrario, Ulpiano habría adherido a la razón originaria de la intervención pretoria, dirigida solamente a la tutela de la navegabilidad de los ríos públicos al proponer la serie de interdictos citados, salvo la excepción que podría ya el intento del pretor estar dirigido a tutelar, sea más limitadamente de cuanto no entendiese Labeón y tal vez por impulso de su pensamiento, el uso común de los ríos públicos contra el facere o el immittere por el cual aliter aqua fluat quam priore aestate fluxit.

Para otros, simplemente la falta de adjetivación se explica por el hecho que al jurista debía aparecer superfluo repetir publicum allí donde toda la discusión argumental giraba entorno al carácter público de los ríos, y al procedimiento del de fluminibus que, en cuanto tal, es ejercitable sólo en el caso de los ríos navegables que como es notorio constituyen una especie de la categoría de los ríos públicos. Y el remedio encuentra razón de ser contra la inercia del propietario ribereño que omitiese cumplir el mantenimiento, por ej., de la limpieza del lecho por la acumulación de desechos. Sólo en tal caso Labeón parece admitir al tercero a una forma de autotutela, consintiéndole penetrar en el fundo en el cual se encontrase la causa a remover sin que el propietario pudiese cumplir con daño suyo actos de impedimento. La purgatio de la cual habla Labeón se referiría entonces, como todas las definiciones de purgare presentes en los comentarios ad edictum, salvo ciertas diferencias debido al diverso contexto, a la remoción de los desechos pero no a la descontaminación de los lugares. ${ }^{32}$

${ }^{30}$ ULPIANO; Comentarios al Edicto, libro LXVIII. Mas el Pretor no prohíbe todo lo que se hace en un río público o en la orilla, sino si se hiciera algo por lo que se hagan peores la estancia en el río y la navegación. Luego este interdicto se refiere solamente a los ríos públicos, que son navegables, y no se refiere a los demás. Pero escribe Labeon, que no es injusto que también si en río, que no sea navegable, se hiciera algo de modo que se seque, o se impida la corriente de agua, competa el interdicto útil, para que no se haga violencia a uno para que pueda quitar, demoler, limpiar, o restablecer en su primer estado, a arbitrio de hombre bueno, la obra que se haya hecho en el cauce del rio o en la orilla de modo de que se haga peor el paso, o la corriente del rio.

31 A. DI PORTO, La tutela della "salubritas" fra editto e giurisprudenza. Il ruolo di Labeone. I. Acque, en BIDR 91 (1988), 568-569. Asimismo, ALBURQUERQUE, Interdictum ne quid in flumine publico repave eius fiat, quo peius navigetur (D. 43.12.1pr.) cit., 220-223, Ulpiano no pretende desconectarse de esta posible extensión en sentido amplio, pero tampoco parece querer distanciarse totalmente de la previsión pretoria inicial, de lo que se podría deducir la tendencia labeoniana -apoyada en parte por Ulpiano- a evidenciar las lagunas de la disciplina interdictal.

${ }^{32}$ Para M. FIORENTINI, Precedenti di diritto ambientale a Roma? I. La contaminazione delle acque en INDEX 34 (2006), 369-370, sería necesario distinguir, por lo tanto, las causas de simple obstrucción debida al depósito de materiales inertes, como limo y basura, de aquellas que provocan alteraciones químicas o 
El Pretor prohíbe, además, que se impidan reparaciones a través de obras en un río público o en su orilla, sea para proteger la orilla o su campo, que está cerca de la orilla con tal que con ella no se haga peor su navegación, si se dio caución o fianza de daño que amenazara, por diez años, según arbitrio de hombre bueno, o si en él no consiste que no se de caución o fianza, cfr. Ulp., 68 ad ed., D.43.15.1pr.:

Praetor ait: 'Quo minus illi in flumine publico ripave eius opus facere ripae agrive qui circa ripam est tuendi causa liceat, dum ne ob id navigatio deterior fiat, si tibi damni infecti in annos decem viri boni arbitratu vel cautum vel satisdatum est aut per illum non stat, quo minus viri boni arbitratu caveatur vel satisdetur, vim fieri veto' ${ }^{33}$

Y Ulp., 68 ad ed., D.43.12.1.17-19, refiere la misma opinión de Labeón también respecto al mar y sus costas y a los ríos públicos no navegables:

17. Si in mari aliquid fiat, Labeo competere tale interdictum: "ne quid in mari inve litore' 'quo portus, statio iterve navigio deterius fiat'.

\section{Sed et si in flumine publico, non tamen navigabili fiat, idem putat. ${ }^{34}$}

Es decir que si se perjudica el usus publicus por cualquier tipo de obra o por una inmisión que entorpezca el tránsito de las naves, la estancia o la utilización del puerto, el jurista augusteo no duda en señalar la aplicabilidad del interdicto. En ello, las diferencias de régimen entre los ríos públicos en su conjunto, el mar y sus costas, respecto a la libertad de uso, y la supuesta necesidad de autorización preventiva para los actos que excedan del uso normal, podrían parecer menos sustanciales, o incluso, más aparentes que reales, resultando incuestionable que la búsqueda del aprovechamiento y conservación de los ríos públicos y de los mares, persevere en los juristas. Por otra parte, parece más aceptable que cualquiera pueda

bacteriales. Los antiguos no disponían de los instrumentos de conocimiento aptos para combatir los peligros inherentes a éstos últimos, si bien, sobre el plano empírico, supiesen que, por ej., el plomo era peligroso para el agua conducida en las tuberías, tanto que Vitr. 8.6.10-11, describiendo el colorido pálido de los artifices plumbarii, justamente relacionado con una sintomatología de envenenamiento de inhalación de vapores de plomo, aconsejaba el uso de tubuli de terracota, que conducían agua mucho más salubre de aquella conducida en fistulae de plomo. En cuanto a las otras formas de contaminación, surge la duda que los Romanos hayan tenido que ver alguna vez con ellas, y, en todo caso, parece al A. haber demostrado que, allí donde los textos jurídicos hablan de purgare, se refieren constantemente a la obra de liberación de las alcantarillas y de los canales de las obstrucciones provocadas por los aportes inertes o por los desechos descargados. Para ALBURQUERQUE, Interdictum ne quid in flumine publico repave eius fiat, quo peius navigetur (D. 43.12.1pr.) cit., 217-218, 226227, 237, es claro, sin embargo, que la navegabilidad de los ríos no es requisito determinante para establecer la publicidad de ellos, aunque la actividad protegida principalmente sea también sin dudas la navegación. En cuanto a las orillas, son públicas en cuanto al uso, pero pueden pertenecer a los ribereños, por lo tanto, pueden ser públicas o privadas, pero se considerarán siempre destinadas al uso público, especialmente cuando formen parte de un río público. En fin, la reflexión jurídica romana parece mantener con trazos firmes y seguros la publicidad del cauce de un río público, y expone con suficiente claridad que si el río abandona su álveo iniciando su recorrido por otro nuevo, lo que se realice en el cauce anterior no estará sujeto a este interdicto, pues ciertamente deja de ser público, cfr. Ulp. 68 ad ed., D. 43.12.1.7.

${ }^{33}$ ULPIANO; Comentarios al Edicto, Libro LXVIII. - Dice el Pretor: Vedo que se haga violencia para que a uno no le sea lícito hacer obra en río público o en su orilla para proteger la orilla o un campo, que está cerca de la orilla, con tal que con ella no se haga peor la navegación, si se te dio caución o fianza a arbitrio de hombre bueno.

${ }^{34}$ ULPIANO; Comentarios al Edicto, libro LXVIII. 17. Si en el mar se hiciera alguna cosa, dice Labeon que compete este interdicto; "no se haga en el mar, o en el litoral, alguna cosa por la que se deteriore para las embarcaciones el puerto, la estancia o el paso". 18. Pero lo mismo opina también si se hiciera en río público, pero no navegable. 
solicitar el interdicto, sin que necesariamente haya sido objeto de un perjuicio efectivo, contra toda persona que haya perjudicado la navegación o la estancia, y a la legitimación popular activa hace pensar la ausencia de referencia en la fórmula edictal de la persona idónea para la posible reclamación. En cuanto a la legitimación pasiva, en el interdicto restitutorio se amplía desde el autor inicial, hasta aquel que mantiene los obstáculos específicos. ${ }^{35}$

Para algunos autores, no existe en estos textos un mínimo punto de apoyo para poder insertar en la noción de facere e immittere perjudiciales a la navegabilidad marina aquella de contaminare. Aunque en abstracto no se puede excluir que la contaminatio pudiese ser vista como forma posible de immissio, la circunstancia que por un lado el texto calla completamente sobre el punto, y por el otro los juristas no hacen alguna referencia en propósito, hace surgir fundadas dudas sobre el hecho que los Romanos (el pretor, los juristas, la praxis) hayan debatido sobre el problema. ${ }^{36}$ Otros, creen que con tal grupo de intervenciones edictales se tendría en miras en particular la navegabilidad de los ríos con fines de lucro, y sólo marginalmente la salubritas de las aguas, ella se calificaría en términos modernos como un mero interés indirectamente protegido. ${ }^{37}$

El par. 19. contiene, por su parte, el interdicto restitutorio respecto a los ríos públicos y sus orillas:

Deinde ait praetor: 'Quod in flumine publico ripave eius fiat sive quid in id flumen ripamve eius immissum habes, quo statio iterve navigio deterior sit fiat, restituas' ${ }^{38}$

También en Ulp., 68 ad ed., D.43.13.1pr., 1, se encuentra el interdicto prohibitorio referido específicamente al cambio de corriente del agua estival, en caso de que se haga o introduzca algo en un río público o en su orilla; ello así, con el objeto de que no mengüen los ríos con derivaciones no concedidas, o que cambiado el cauce no se causen perjuicios a los vecinos:

Ait praetor: 'In flumine publico inve ripa eius facere aut in id flumen ripamve eius immittere, quo aliter aqua fluat, quam priore aestate fluxit, veto'.

1.Hoc interdicto prospexit praetor, ne derivationibus minus concessis flumina excrescant vel mutatus alveus vicinis iniuriam aliquam adferat. ${ }^{39}$

${ }^{35}$ ALBURQUERQUE, Interdictum ne quid in flumine publico repave eius fiat, quo peius navigetur (D. 43.12.1pr.) cit., 252, 254-255, 260.

${ }^{36}$ FIORENTINI, Precedenti di diritto ambientale a Roma? I. La contaminazione delle acque cit., 372.

${ }^{37}$ Según F. LAMBERTI, Letture. «Principio Responsabilità» a Roma?, en LABEO 45 (1999), 130131, al igual que hoy donde las únicas modificaciones sensibles fueron impuestas por obra de la Comunidad Europea, pero no en los singulares Estados, por ello, auspicia un cambio de mentalidad, y una inversión de tendencia, respecto al comportamiento heredado, en tal campo, de los romanos. Ello se impone, sobre todo dado el cambio de las condiciones históricas y tecnológicas, por ello el «principio responsabilidad» debe ser destinado a informar, en el futuro, las opciones del legislador nacional en campo ambiental.

${ }^{38}$ ULPIANO; Comentarios al Edicto, libro LXVIII. 19. Después dice el Pretor: "Restablece en su primer estado lo que se haga en un río público o en su orilla, o lo que en este río o en su orilla tienes introducido, por lo que sea o se haga peor para las embarcaciones la estancia o el paso".

${ }^{39}$ ULPIANO; Comentarios al Edicto, libro LXVIII. Dice el Pretor: "Vedo hacer en río público o en su orilla, o introducir en este río o en su orilla, cosa por la que corra el agua de otro modo que como corrió en el anterior estío". 1. Con este interdicto proveyó el Pretor a que no mengüen los ríos con derivaciones no concedidas, o a que cambiado el cauce no se cause perjuicio alguno a los vecinos. 
Ulp., 68 ad ed., D.43.13.1.2, aclara que este interdicto se refiere a los ríos públicos navegables o no, con lo cual recoge la anterior opinión de Labeón como si fuera una opinión consolidada:

\section{Pertinet autem ad flumina publica, sive navigabilia sunt sive non sunt. ${ }^{40}$}

Asimismo, en Ulp., 68 ad ed., D.43.12.1pr., 1, se encuentra por un lado el interdicto prohibitorio de aquello que pueda hacerse o introducirse en río público o en su orilla, por la cual se haga peor para las naves la estancia o el paso, y por otro lado, describe el significado de la palabra "Río", que se distingue del arroyo por su magnitud o por la apreciación de los habitantes de los alrededores:

Ait praetor: 'Ne quid in flumine publico ripave eius facias neve quid in flumine publico neve in ripa eius immittas, quo statio iterve navigio deterior sit fiat'.

\section{Flumen a rivo magnitudine discernendum est aut existimatione circumcolentium. ${ }^{41}$}

Este interdicto, como indica el mismo Ulpiano, no tendrá eficacia en relación a los ríos privados, que no presentan diferencias sustanciales respecto a los demás lugares privados, repeticiones ulpianeas que encuentran acogida también cuando comenta el interdicto ut in flumine publico navigare liceat (D. 43.14.1.2 $2^{42}$ ). Ello también atestigua, por ende, la existencia de ríos públicos y privados y un régimen de defensa diferente. Resulta significativa, además, la necesidad que sintieron los Romanos de añadir el adjetivo publicum al término sustantivo flumen, cuando querían hablar de ríos públicos. Por otra parte, la distinción entre arroyos y ríos por el tamaño o magnitud y la estimación de los vecinos, es una abstracción que a algunos parece demasiado compleja, y podría incluso dar demasiado margen a los posibles intereses privados si los consideramos como criterios absolutamente definitivos, aunque se encuadra bien en las previsiones de la jurisprudencia clásica, que tiende a deducir el criterio de la publicidad de la naturaleza física de los cursos de agua integrada por la valoración social, o los que tuvieran reconocida tal cualidad en función de las especiales circunstancias geográficas o singular valoración social. No se descarta tampoco una posible evolución dubitativa de Ulpiano al respecto. De todos modos, no es una definición, para algunos autores, que nos permita comprender mejor el alcance efectivo de las dos figuras de río público y río privado, para distinguir claramente el campo aplicativo al cual se extiende el interdicto, y la adecuada misión protectora del uso colectivo de los ríos públicos. La diferencia entre arroyos y torrentes, no significa por lo demás, que todos los torrentes sean privados; y la distinción tiene importancia exclusivamente en relación al interdicto que Ulpiano comenta en esta sede, ya que al servir para proteger la navegación, no parece demasiado lógico que se introduzcan cursos de agua más pequeños por no reunir las condiciones idóneas para la misma. Por otra parte, el criterio de la perennidad no es suficiente por sí sólo para determinar la publicidad de un curso de agua, pues no todo curso de agua perenne como tal es público, es preciso entonces que se trate de un curso de agua considerable. El fragmento proporcionaría una prueba convincente de que los rivi perennes

${ }^{40}$ ULPIANO; Comentarios al Edicto, libro LXVIII. Mas se refiere a los ríos públicos, ya si son navegables, ya si no lo son.

${ }^{41}$ ULPIANO; Comentarios al Edicto, libro LXVIII. Dice el Pretor: "No hagas en río público o en su orilla, $n i$ introduzcas en río público ni en su orilla, cosa alguna por la cual se haga peor para las naves la estancia o el paso". 1. El "Río" se ha de distinguir del arroyo por su magnitud, o por la apreciación de los habitantes de los alrededores.

${ }^{42}$ ULPIANUS libro sexagensimo octavo ad edictum. Si privata sunt supra scripta, interdictum cessat. 
constituyen solamente una subespecie de los flumina publica, jurídicamente no bien distinguida por los romanos. ${ }^{43}$

En fin, también en Ulp., 68 ad ed., D.43.13.1.11, se encuentra el interdicto restitutorio por aquello que se hubiera hecho o introducido en río público o en su orilla, por causa de lo cual el agua corriere de otro modo respecto al anterior estío:

Deinde ait praetor: 'Quod in flumine publico ripave eius factum sive quid in flumen ripamve eius immissum habes, si ob id aliter aqua fluit atque uti priore aestate fluxit, restituas, ${ }^{44}$

Algunos autores notan la amplitud de la previsión labeoniana también en estos interdictos, más allá del hecho que ella se refiera sólo a los ríos públicos o también a los privados y, sobre lo cual no hay dudas, a los ríos navegables y a los no navegables. Ello así, porque referirse a un opus, hecho in alveo fluminis ripave, que vuelva deterior el iter cursus fluminis, significaría tomar en consideración un catálogo amplísimo de posibilidades de daño del río, respecto al cual las dos hipótesis formuladas en la inicial perspectiva del caso exarescere y aquae cursus impediri - representan no más que dos casos indicados a título de ejemplo. Por lo demás, el elenco de las actividades protegidas por el interdicto para la recomposición del iter cursus fluminis vuelto deterior, ello es tollere demoliri purgare restituere, confirmaría la amplitud del citado catálogo. La mención del purgare revelaría un ámbito de aplicación del interdicto, configurado por Labeón, que comprende también aquellas obras que, en un modo u otro, producen -en sentido lato- la contaminación del río. Previsión que se inserta perfectamente en el ámbito de un diseño complejo del jurisconsulto augusteo dirigido a la tutela de la salubritas, que parece abarcar toda posible forma de daño de los ríos y, tal vez también de los privados, o de los flumina non mediocria que discurren sobre fundos pertenecientes a un diverso propietario. Pero además, al fondo de la previsión

${ }^{43}$ ALBURQUERQUE, Interdictum ne quid in flumine publico repave eius fiat, quo peius navigetur (D. 43.12.1pr.) cit., 204-205 y nt. (32), 208-209 y nt. (49), 210-211 y nt. (50), 241-247, 250, v. también D. 43.12.1.19; 43.12.1pr.; 43.13.1pr.; 43.13.1.11; 43.14.1pr.; 43.15.1pr. Las orillas de los ríos públicos se caracterizan más por la disposición al uso común que por su publicidad. El carácter público o privado de las orillas, representa una de las grandes polémicas doctrinales, pero una larga tradición jurídica ha entendido su especial función como necesaria para su uso general. Lab. 6 pith. a Paul. Epit., D. 41.1.65.1, es determinante en cuanto a la publicidad de las orillas de los ríos perennes, pero Ulp. 52 ad ed., D. 39.1.1.1, para demostrar la inaplicabilidad del edicto de obra nueva cuando la obra ya había sido terminada, detalla los instrumentos válidos a los que habrá que recurrir para subsanar esta imposibilidad, refiriéndose tanto al interdicto restitutorio quod vi aut clam, como al interdicto de lo hecho en lugar sagrado o religioso y el interdicto de lo hecho en río o ribera públicos. De aquí la relativa publicidad de las orillas se infiere, ya que Ulpiano se remite al interdicto sobre lo que se haya hecho en río público o en ribera pública. Entre los textos que reconocen la propiedad privada de las orillas, o bien destacan su publicidad exclusivamente respecto al usus publicus, es decir, que continúan perteneciendo a los ribereños, aunque estén sujetas al uso común, se encuentra Gai, 2 Rer. Cott. Aur., D. 1.8.5, quien destaca la publicidad de las orillas por derecho de gentes, con el mismo argumento que el criterio utilizado para determinar la publicidad de los ríos. Asimismo, en I. 2.1.5, se reconoce el usus publicus por derecho de gentes de las costas como del mar. La propiedad privada de las orillas se presupone en numerosos textos (cuando son de naturaleza privada los fundos adyacentes al río público), si bien, la limitación parcial a esta propiedad privada la determina, por motivos de utilidad pública, el uso normal reconocido a todos los ciudadanos para el desempeño de todas las actividades propias de la navegación, que tendrá que soportar el propietario del terreno si no quiere verse sometido a las previsiones interdictales referidas. Por lo tanto, el agua corriente del río es una res communis omnium; el cauce del río es público, como el suelo romano de dominio público, pero está completamente sujeto al uso público; las orillas pueden ser privadas, pero totalmente disponibles para el uso público; el río, en su conjunto, es una res publica, pero iuris gentium.

${ }^{44}$ ULPIANO; Comentarios al Edicto, libro LXVIII. Después dice el Pretor: "Restablece a su primer estado lo que en río público o en su orilla tienes hecho, o lo que en el río o en su orilla tienes introducido, si por causa de esto el agua corre de otro modo que como corrió en el anterior estío". 
labeoniana parecería situarse la defensa del estado de los ríos. Se podrá decir que el jurista con el interdicto en examen entiende tutelar el uso común de los ríos, lo cual es cierto, pero está configurado de un modo tal que el uso común no debe volver deterior el iter cursus fluminis, porque de lo contrario cae bajo la aplicación del interdicto mismo. Por lo tanto, sería el río, su estado natural, o el ambiente fluvial el que resultaría tutelado en definitiva. Todo ello, más allá de una esquemática relación de causa (Labeón) y efecto (pretor), en el cuadro de un complejo proceso dialéctico entre jurisprudencia y edicto del pretor en el período entre tardía república y principios del imperio, hasta el momento en el cual se agotará el impulso creativo del mismo edicto. ${ }^{45}$

\section{1.- Operis novi nuntiatio}

Cfr. afirma Ulpiano, 52 ad ed., D.39.1.1.1, 11-12, el remedio del Edicto y denuncia de obra nueva se establecieron contra las obras futuras, no contra las hechas, es decir, contra las que aún no se hicieron, para que no se hagan. Por otro lado, se considera que hace una obra nueva el que o edificando, o demoliendo algo, muda su primitivo aspecto, y no se refiere a todas las obras, sino sólo a aquellas que están unidas al suelo, cuya edificación, o demolición comprende una obra nueva. Por lo tanto, se determinó, que si alguno hiciera sioga, o cortara un árbol, o podara una viña, aunque hace una obra, no se comprende, sin embargo, en este Edicto, porque él se refiere a las obras que se hacen en el suelo:

1. Hoc autem edictum remediumque operis novi nuntiationis adversus futura opera inductum est, non adversus praeterita, hoc est adversus ea quae nondum facta sunt, ne fiant: nam si quid operis fuerit factum, quod fieri non debuit, cessat edictum de operis novi nuntiatione et erit transeundum ad interdictum 'quod vi aut clam factum erit ut restituatur', et 'quod in loco sacro religiosove' et 'quod in flumine publico ripave publica factum erit': nam his interdictis restituetur, si quid illicite factum est.

11. Opus novum facere videtur, qui aut aedificando aut detrahendo aliquid pristinam faciem operis mutat.

12. Hoc autem edictum non omnia opera complectitur, sed ea sola, quae solo coniuncta sunt, quorum aedificatio vel demolitio videtur opus novum continere. Idcirco placuit, si quis messem faciat, arborem succidat, vineam putet, quamquam opus faciat, tamen ad hoc edictum non pertinere, quia ad ea opera, quae in solo fiunt, pertinet hoc edictum. ${ }^{46}$

${ }^{45}$ DI PORTO, La tutela della "salubritas" fra editto e giurisprudenza. Il ruolo di Labeone. I. Acque cit., 565-570. Asimismo, MADDALENA, I beni comuni nel diritto romano: qualche valida idea per gli studiosi odierni cit., 32-33, quien afirma que objeto de estos interdictos, como fácilmente se nota, es siempre el estado del río, mientras la ratio es aquella de no provocar un daño a la navegación. Sin embargo, es claro para el A. que no es posible partir de la destinación al uso público y de la tutela interdictal para afirmar la existencia de las res publicae en general y de las res communes omnium en particular, sino de la originaria pertenencia del territorio al populus, sobre cuya base surge la Comunidad política, que debe extraerse el criterio para la individualización de las res publicae.

${ }^{46}$ ULPIANO; Comentarios al Edicto, libro LII. 1. Mas se estableció este Edicto y este remedio de la denuncia de obra nueva contra las obras futuras, no contra las hechas, esto es, contra las que aún no se hicieron, para que no se hagan; porque si se hubiere hecho alguna obra que no se debió hacer, deja de tener lugar el Edicto de denuncia de obra nueva, y se habrá de recurrir al interdicto de lo que se hubiere hecho violenta o clandestinamente, para que se vuelva al anterior estado, o al de lo que se hubiere hecho en lugar sagrado o religioso, o al de lo que en río público, o en ribera pública; porque con estos interdictos se repondrá a su estado lo que se haya hecho ilícitamente. 11. Se considera que hace una obra nueva el que o edificando, o demoliendo algo, muda el primitivo aspecto de la obra. 12. Mas este edicto no comprende todas las obras, sino aquellas solas que están unidas al suelo, cuya edificación, o demolición parece que comprende una obra nueva. Y por lo tanto 
Es considerado opus novum, por ende, toda alteración o modificación de la fisonomía originaria de los lugares, fuese ella una construcción, o bien una simple ampliación de una obra ya existente o una demolición, también parcial. ${ }^{47}$ No lo es, la provisión de apoyos a un viejo edificio que amenaza el colapso. La denuncia de nueva obra sirve, básicamente, para asegurar al propietario contra obras edificadas en un fundo vecino del cual éste pueda temer un daño ${ }^{48}$, pero la consideración del interés del vecino se tenía en cuenta sólo sucesivamente a la satisfacción del interés de la colectividad a que fuese preservada la estética de la ciudad $\mathrm{y}$, sobre todo, salvaguardada la incolumnidad pública. ${ }^{49}$

Además, la denuncia se hace, no sólo para conservar un derecho privado, o para alejar un perjuicio, sino también para defender un derecho público. Quien denuncia lo hace porque tiene un derecho para prohibir, o para que por el daño que amenace se de caución por el que en un lugar público o privado emprende alguna obra, o si se hiciere alguna cosa contra las leyes o los edictos de los Príncipes, que se dieron respecto a la forma de los edificios, o en lugar sagrado, o religioso, o público, o en la ribera de un río, por cuyas causas se dan también los interdictos, cfr. Ulp., 52 ad ed., D.39.1.1.16-18:

16. Nuntiatio fit aut iuris nostri conservandi causa aut damni depellendi aut publici iuris tuendi gratia.

17. Nuntiamus autem, quia ius aliquid prohibendi habemus: vel ut damni infecti caveatur nobis ab eo, qui forte in publico vel in privato quid molitur: aut si quid contra leges edictave principum. Quae ad modum aedificiorum facta sunt, fiet, vel in sacro vel in loco religioso, vel in publico ripave fluminis, quibus ex causis et interdicta proponuntur.

18. Quod si quis in mare vel in litore aedificet, licet in suo non aedificet, iure tamen gentium suum facit: si quis igitur velit ibi aedificantem prohibere, nullo iure prohibet, neque opus novum nuntiare nisi ex una causa potest, si forte damni infecti velit sibi caveri. ${ }^{50}$

se determinó, que si alguno hiciera sioga, o cortara un árbol, o podara una viña, aunque hace una obra, no se comprende, sin embargo, en este Edicto, porque este Edicto se refiere a las obras que se hacen en el suelo.

${ }^{47}$ F. FASOLINO, Interessi della collettività e dei vicini nell' "operis novi nuntiatio» en LABEO 45 (1999), 42-43 y nt. (11).

${ }^{48}$ FIORENTINI, Struttura ed esercizio della servitù d'acqua cit., 178, sin embargo, Ulpiano en D. 39.1.5.12 (52 ad ed.), recuerda una excepción, referida a dos exigencias contrapuestas: aquella del propietario que se siente amenazado por la próxima ejecución de la obra, y desea servirse de la denuncia de nueva obra, y aquella del sujeto que se dispone a erigir una obra para evitar un peligro inminente. Entre las dos pretensiones, la preferencia debe ser medida caso por caso, con una prudente valoración empírica, sobre cuál de las dos exigencias tenga más título para ser valorizada, allí cuando una dilatio de la construcción de la obra produzca el riesgo de generar un peligro a cargo del constructor, la nuntiatio puede tranquilamente ser dejada de lado. En este caso, el denunciante podrá pedir un interdicto, y en sede de proceso interdictal (al cual Ulpiano se refiere afirmando que apud iudicem quaeri debere, an talia opera fuerint, ut contemni nuntiatio deberet) el punto a probar será precisamente la urgencia de la obra. Diverso es cuando el interés público prevalece sobre el privado, en caso de refectio de un canal o drenaje, cfr. D. 39.1.5.11.

${ }^{49}$ FASOLINO, Interessi della collettività e dei vicini nell'«operis novi nuntiatio» cit., 44.

${ }^{50}$ ULPIANO; Comentarios al Edicto, libro LXVIII.- 16. La denuncia se hace, ó para conservar un derecho nuestro, ó para alejar un perjuicio ó para defender un derecho público. 17.- Pero denunciamos, porque tenemos algún derecho para prohibir, ó para que el daño que amenaza se nos dé caución por el que acaso en un lugar público ó en otro privado emprende alguna obra, ó si se hiciere alguna cosa contra las leyes ó los edictos de los Príncipes, que se dieron respecto a la forma de los edificios, ó en lugar sagrado, ó religioso, ó público, ó en la ribera de un rio, por cuyas causas se dan también los interdictos. 18.- Pero si alguno edificara en el mar o en la orilla, aunque no edifique en lo suyo, lo hace sin embargo, suyo por el derecho de gentes. Así, púes si alguno quisiera prohibirle que edifique allí; no se lo prohíbe con derecho alguno; y no puede denunciar la obra nueva sino por una sola causa, si acaso quisiera que se le diese caución por daño que le amenace. Cfr. 
Habría bastado, por ende, la realización de una de las dos condiciones para hacer posible el ejercicio del remedio. Si la matriz común que conecta la nuntiatio publica a aquella conservandi causa comporta inevitablemente la aún parcial coincidencia de las respectivas disciplinas, precisamente el interés público protegido en el caso en examen figura como factor discriminante respecto a las otras causae nuntiationis. ${ }^{51}$

Es más, si se hiciera alguna obra nueva en un lugar público, todos los ciudadanos pueden denunciarla, cfr. Ulp., 52 ad ed., D.39.1.3.4:

Si in publico aliquid fiat, omnes cives opus novum nuntiare possunt: ${ }^{52}$

Ello así, porque, según Paulo, importa a la República admitir a muchísimos para defender su causa:

Paul., 48 ad ed., D.39.1.4 nam rei publicae interest quam plurimos ad defendendam suam causam admittere. ${ }^{53}$

Lo que parecería admitir además la posibilidad, tal vez, de una denuncia colectiva en estos casos.

\section{2.- Cautio damni infecti}

Asimismo, según Ulp., 53 ad ed., D.39.2.7pr., el Pretor sostuvo que mandará prometer en nombre propio, o que en nombre de otro se dé fianza por el daño que amenaza. Si la obra se hiciera en río público o ribera, la fianza será de diez años:

Praetor ait:'damni infecti suo nomine promitti, alieno satisdari iubebo ei, qui iuraverit non calumniae causa id se postulare eumve cuius nomine aget postulaturum fuisse, in eam diem, quam causa cognita statuero. Si controversia erit, dominus sit nec ne qui cavebit, sub exceptione satisdari iubebo. De eo opere, quod in flumine publico ripave eius fiet, in annos decem satisdari iubebo. Eum, cui ita non cavebitur, in possessionem eius rei, cuius nomine ut caveatur postulabitur, ire et, cum iusta causa esse videbitur, etiam possidere iubebo. in eum, qui neque caverit neque in possessione esse neque possidere passus erit, iudicium dabo, ut tantum praestet, quantum praestare eum oporteret, si de ea re ex decreto

ANKUM, «Litora maris» et «longi temporis praescriptio» cit., 367, los juristas hacen una interpretación extensiva de este pasaje hacia aquel que quiere hacer construcciones sobre los litora maris, según Ulpiano. L. PELLECCHI, Contributi palingenetici allo studio dell'operis novi nuntiatio, en SDHI 68 (2002), 180-181, de aquí (fr. 17) extrae también la conexión entre conceptio personalizada y obras hechas en lugares no de propiedad del denunciado. Una vez personalizada la caución, relacionando el opus a restituir al hecho del promitente, debía aparecer oportuno contemplar también el hecho del heredero, de modo que al denunciante fuese asegurada la posibilidad de accionar directamente ex stipulatu en relación a las construcciones realizadas o continuadas en el fundo denunciado después de la muerte del promitente.

${ }^{51}$ Sobre el rol no marginal desarrollado en edad clásica por la nuntiatio publica, v. P. SANTINI, «Operis novi nuntiatio»e interesse pubblico, en INDEX 30 (2002), 431-432, 434-436; F. SITZIA, Rec. a Gianni Santucci, Operis novi nuntiatio iuris publici tuendi gratia, Cedam, Padova 2001, pp. 170, en SDHI 69 (2003), 685, 687, 688; y G. FALCONE, Rec. a Santucci G., Operis novi nuntiatio iuris publici tuendi gratia [Pubblicazioni del Dipartimento di scienze giuridiche Università di Trento, 34] (Padova, Cedam, 2001) p. XII + $170,378-384$.

${ }^{52}$ ULPIANO; Comentarios al Edicto, libro LII.- Si se hiciera alguna en un lugar público, todos los ciudadanos pueden denunciar la obra nueva.

53 PAULO; Comentarios al Edicto, libro XLVIII.- porque le importa a la república admitir a muchísimos para defender su causa. 
meo eiusve, cuius de ea re iurisdictio fuit quae mea est, cautum fuisset. Eius rei nomine, in cuius possessionem misero, si ab eo, qui in possessione erit, damni infecti nomine satisdabitur, eum, cui non satisdabitur, simul in possessione esse iubebo'.

\section{4.- Referencias a interdictos sobre los lagos}

Existen asimismo en las fuentes jurídicas romanas, algunas referencias a interdictos para defender el buen estado y acceso a los lagos. Dentro de éstos, el Pretor daba o interponía un interdicto para que sea lícito navegar por lago, canal, o estanque público, cfr. Ulp., 68 ad ed., D.43.14.1pr.:

Praetor ait: 'Quo minus illi in flumine publico navem ratem agere quove minus per ripam onerare exonerare liceat, vim fieri veto. Item ut per lacum fossam stagnum publicum navigare liceat, interdicam, ${ }^{54}$

Está presente también un interdicto prohibitorio que veda la violencia para la limpieza y restauración de fuentes (con extensión, parecería, también a los putei, lacus y piscinae ${ }^{55}$ ), con el fin de contener el agua y usar de ella de acuerdo al modo como se usó durante ese año, teniendo derecho para ello, es decir, sin violencia, clandestinidad o precariedad, cfr. Ulp., 70 ad ed., D.43.22.1.6:

Deinde ait praetor: 'Quo minus fontem, quo de agitur, purges reficias, ut aquam coercere utique ea possis, dum ne aliter utaris, atque uti hoc anno non vi non clam non precario ab illo usus es, vim fieri veto' ${ }^{56}$

Sólo a través de una interpretación jurisprudencial se habría afirmado la extensión del interdicto en cuestión, cfr. Ulp. 70 ad ed., D.43.22.1.10: Sed et de lacu (lago como fuente alimentada de aguas vivas, incluso de los acueductos públicos que por lo general fluían hacia ellos y que podían ser usados por los particulares para extraer agua) puteo piscina (de aguas sea naturales que artificiales destinadas en general como abrevadero de los animales) reficiendis purgandis hoc interdictum competit. ${ }^{7}$

Por último, Ulp., 70 ad ed., D.43.21.3pr, 3-5, nos refiere que Servio escribió que si alguien hiciera alguna obra con la que mejor conserve el agua, o la contenga, no se le impide impunemente, aunque Ulpiano opina lo contrario si se tratara de galería cubierta, porque allí debería demostrarse mayor utilidad de su adversario. Asimismo, si el agua fuese conducida a un lago, y de allí fuera llevada por muchos acueductos, tendrá este interdicto útil el que quiera reparar el mismo lago, así sean acequias que se hallen establecidas en terreno público o privado, de agua caliente o fría:

${ }^{54}$ ULPIANO; Comentarios al Edicto, libro LXVIII.- Dice el Pretor: "Vedo que se le haga a uno violencia para que no le sea lícito conducir nave o barca por río público, o cargarla o descargarla en la orilla. También interpondré interdicto para que sea lícito navegar por lago, canal, ó estanque público".

55 A. BURDESE, Tutela privatistica del ambiente e diritto romano, en Rivista di Diritto Civile 35 (1989), 509.

${ }^{56}$ ULPIANO; Comentarios al Edicto, libro LXX. Después dice el pretor: "vedo que se haga violencia para que no limpies y restaures la fuente de que se trata, para que puedas contener el agua y usar de ella, con tal que no uses de ella de otro modo que como usaste en este año, ni violenta, ni clandestinamente, ni en precario".

${ }^{57}$ Así CAPOGROSSI COLOGNESI, Ricerche sulla struttura delle servitù d'acqua in diritto romano cit., 124. 
Servius autem scribit aliter duci aquam, quae ante per specus ducta est, si nunc per apertum ducatur: nam si operis aliquid faciat quis, quo magis aquam conservet vel contineat, non impune prohiberi. Ego et in specu contra, si non maior utilitas versetur adversarii.

3. Si aqua in unum lacum conducatur et inde per plures ductus ducatur, hoc interdictum utile erit volenti reficere ipsum lacum.

4. Hoc interdictum ad omnes rivos pertinet, sive in publico sive in privato sint constituti.

\section{Sed et si calidae aquae rivus sit, de hoc reficiendo competit interdictum. ${ }^{58}$}

El lacus del cual habla el paso no es, sin embargo, verosímilmente, un lago natural, sino una cuenca de recolección de las aguas. El sistema al cual alude el texto prevé un único canal aductor, que alimenta la recolección, del cual se desprenden luego los canales derivadores que conducen el agua hacia cada uno de los usuarios. Parecería poder desumirse que la cuenca pertenece a todos los usuarios, uno de los cuales decide, por su propia iniciativa, realizar actos de conservación. La razón por la cual le son opuestos actos de prohibitio depende probablemente de la necesidad de vaciar la cuenca, lo que provocaría, como consecuencia inevitable, la falta de aprovisionamiento hídrico de los otros usuarios (se trataría entonces de un caso de acceso al agua más que de conservación). No obstante este prejuicio, Ulpiano se pronuncia sin duda alguna en el sentido de la ilicitud de la vis, que por lo tanto podrá ser inhibida con el interdicto. ${ }^{59}$

\section{5.- Algunos casos actuales en Argentina y la reforma del Código Civil}

En Argentina, el art. 2639 del Código Civil vigente, establece que los propietarios limítrofes con ríos o canales que sirven a la comunicación por agua, están obligados a dejar un camino público de 35 metros hasta la orilla y que no pueden intervenir en ese espacio: "Los propietarios limítrofes con los ríos o con canales que sirven a la comunicación por agua, están obligados a dejar una calle o camino público de treinta y cinco metros hasta la orilla del río, o del canal, sin ninguna indemnización. Los propietarios ribereños no pueden hacer en ese espacio ninguna construcción, ni reparar las antiguas que existen, ni deteriorar el terreno en manera alguna". No obstante, actualmente está costando mucho sacrificio que los privados cumplan con el libre tránsito existente de costas de ríos, arroyos y lagos, sobre todo en la Patagonia. La costa este del lago Nahuel Huapi, en Bariloche, es una franja de 25 $\mathrm{km}$ sembrada de obstáculos que luce cada vez más fragmentada por propiedades que avanzan sobre las playas. Los dueños construyen muelles, rellenan sin permiso y bloquean el paso con alambres o barreras naturales. Los controles parecen ineficaces. ${ }^{60}$

\footnotetext{
${ }^{58}$ ULPIANO; Comentarios al Edicto, libro LXX. Mas escribe Servio, que se conduce de otro modo el agua, que antes fue conducida por galería cubierta, si ahora fuese conducida por otra abierta; pero si uno hiciera alguna obra con la que mejor conserve el agua, o la contenga, no se le impide impunemente; yo aun tratándose de galería cubierta opino al contrario, si no mediara mayor utilidad de su adversario. 3. Si el agua fuese conducida a un lago, y de allí fuera llevada por muchos acueductos, tendrá este interdicto útil el que quiera reparar el mismo lago. 4. Este interdicto es pertinente para todas las acequias, ya se hallen establecidas en terreno público, ya en privado. 5. Pero aunque la acequia sea de agua caliente, compete este interdicto para repararla.

${ }^{59}$ FIORENTINI, Struttura ed esercizio della servitù d'acqua cit., 166.

${ }^{60}$ V. G. SANCHEZ, El acceso a las costas de ríos y lagos, cada vez más restringido, en Clarín, domingo 23 de septiembre de 2012, 44 .
} 
Por otra parte, existen al menos 19 acciones judiciales contra privados que edificaron sobre la costa hoteles o casas lujosas. De las 99 bajadas públicas al espejo de agua, más de la mitad están bloqueadas. Existen mega casas en construcción que parecen posarse casi sobre el agua, por encima de la línea de ribera que determina la frontera entre lo público y lo privado. Incluso, está casi naturalizada la costumbre que los pobladores deben pedir permiso a condominios privados para llegar hasta la orilla del lago o de los ríos, y a tener que abrir tranqueras o cruzar alambrados para llegar a la orilla. Es más, se han cercado playas, que antes todos usaban. ${ }^{61}$

Todo ello ha recreado un escenario de naturaleza cercada que ha planteado otro interrogante y debate de fondo acerca del uso que hacen del recurso acuífero los que controlan el acceso. En Esquel, por ejemplo, se espera desde hace más de un año que el municipio convierta en ordenanza un proyecto para proteger el libre acceso a las costas. Ello así, debido a que son muy conocidas las restricciones que impone la multinacional Benetton al libre acceso al río Chubut. Su propiedad ocupa casi la cuarta parte del curso de ese río, el más importante de la Provincia. Y en fin, sucedió también lamentablemente un caso trágico en Argentina, ya que un chico fue asesinado por el guardia de un complejo de cabañas mientras pescaba en las costas de un río "privatizado" de San Martín de los Andes. ${ }^{62}$

En razón de lo expuesto, ha causado una gran polémica el proyecto de reforma del Código Civil Argentino en marcha, que en su art. 1974 reduce 20 metros el espacio de costas libres, al disponer que el dueño de un inmueble colindante con orillas de cauces o sus riberas, aptos para el transporte por agua, debe dejar libre una franja de terreno de quince metros de ancho. Se trataría del regreso a la medida del "camino de sirga", algo que estaba en desuso. Pero se observa que ello produciría un perjuicio para la naturaleza y una restricción mayor a que la gente pueda hacer uso de un bien común. Esos $35 \mathrm{~m}$ son un corredor biológico que garantiza la conservación de la biodiversidad, y con la reducción habrá un beneficio extra para los propietarios ya que antes no podían intervenir en ese espacio. Éste les pertenecía, pero debían dejar libre el camino público, es decir que pesaba sobre ellos una restricción al dominio y era ilegal edificar en esa zona. Con la modificación de este aspecto del Código, se teme que podrán cercar más el recurso natural y crear mayores dificultades para acceder a éste, lo que ya sucede de hecho, como fue visto, en muchos lagos y ríos del país. ${ }^{63}$

La riqueza natural de estos bienes comunes, tiene un gran impacto social y es fundamental para el buen vivir de las personas, por lo tanto, se sostiene que el Código debe garantizar el libre acceso, el uso responsable, satisfacer el goce y uso de interés general y el cuidado del mismo. El art. 2369 del Código Civil vigente, es considerado como una norma que garantiza el acceso público a cursos de agua y que presta beneficios al mantenimiento de la biodiversidad. Este camino público cumple una misión clave para preservar ecosistemas costeros y garantizar la libre circulación y el acceso a bienes públicos como ríos y lagos. En el nuevo proyecto, sólo los dueños de terrenos colindantes podrán acceder y gozar de las costas, porque además se suprime el carácter de "camino público" de la franja de tierra, lo que anularía la posibilidad de acceder. ${ }^{64}$

En consecuencia, se ha considerado que el proceso de reforma del Código Civil Argentino debería estar impregnado por el derecho ambiental. No sólo en mayores

\footnotetext{
${ }^{61}$ SANCHEZ, El acceso a las costas de ríos y lagos, cada vez más restringido cit., 44.

${ }^{62}$ SANCHEZ, El acceso a las costas de ríos y lagos, cada vez más restringido cit., 44-45.

${ }^{63} \mathrm{SANCHEZ,} \mathrm{El} \mathrm{acceso} \mathrm{a} \mathrm{las} \mathrm{costas} \mathrm{de} \mathrm{ríos} \mathrm{y} \mathrm{lagos,} \mathrm{cada} \mathrm{vez} \mathrm{más} \mathrm{restringido} \mathrm{cit.,} \mathrm{44-45.}$

${ }^{64}$ E. VIALE, Desmercantilizar la naturaleza, en Clarín, domingo 23 de septiembre de 2012, 45.
} 
restricciones al dominio, atendiendo a la función ambiental de la propiedad, sino con normas que lleven a la desmercantilización de la naturaleza. Frente a la tendencia de "privatizar" la naturaleza hasta lugares impensados, está tomando cada vez más fuerza la transición del concepto de "recursos naturales" al de "bienes comunes". Ello garantizaría su real y pleno goce colectivo, y que ni los particulares ni los Estados tuvieran jurisdicción plena sobre ellos. $^{65}$

\section{6.- Conclusiones}

Es claro que para los Romanos casi todos los ríos y riberas eran públicos. Lo eran sobre todo aquellos de gran envergadura, por su magnitud o abundancia de sus aguas, por la perennidad de ellas, y por la valoración económico-social y apreciación de los habitantes que los necesitaban para satisfacer sus necesidades esenciales. En cuanto a las riberas, también podían ser públicas o privadas, pero se debía respetar su uso público o común iuris gentium así como su conservación.

En defensa de todo ello, existían, como fue visto, una serie de interdictos prohibitorios y restitutorios, así como la posibilidad de denunciar una obra nueva exigiendo a su vez una caución por el daño temido, y la existencia de una legitimación popular.

En cuanto a la acción de injurias, si bien se estableció que en lago de dominio privado se podía impedir a alguien que pesque, no se dice nada respecto al acceso a las riberas y a la posibilidad de otros usos colectivos de los lagos privados, y, por extensión, de los ríos privados.

Se podría pensar que al igual que los ríos, los lagos y sus riberas eran considerados públicos si así era valorado socialmente, por su extensión y utilidad para los usos colectivos, y debía permitirse el uso público (iuris gentium) de las riberas de los lagos aunque fueran privadas.

En consecuencia, el modelo romano parece ser el de acceso libre al uso público (iuris gentium) y conservación de las ripae, independientemente de su carácter privado o público, pero con una fuerte determinación hacia la calificación de público de aquellos ríos y lagos que fueran fundamentales por su extensión y magnitud y por la perennidad de sus aguas, así como por la valoración económico-social y la apreciación de sus habitantes, para satisfacer usos esenciales de interés general.

Ese es el modelo que deberían seguir los Códigos, y es de esperar que también el Código Civil Argentino lo siga en sus próximas reformas, reforzando incluso la tutela procesal en el sentido integral y expedito -interdictos, denuncia de obra nueva, caución por el daño temido- indicado por las fuentes romanas.

${ }^{65}$ VIALE, Desmercantilizar la naturaleza cit., 45. 